\title{
ESTUDO E AVALIAÇÃO DE ADITIVOS NAS PROPRIEDADES DE TINTAS EM PÓ DO TIPO POLIÉSTER EM SUBSTRATOS METÁLICOS E VÍTREOS
}

\author{
M.T.S. NEDOCHETKO ${ }^{1}$, C.R. MARTINS ${ }^{2}$, S. HEYDER ${ }^{2}$, \\ H.G. RIELLA ${ }^{3}$, L.A.D KOSLOWSKI ${ }^{3}$ \\ ${ }^{1}$ Universidade da Região de Joinville, Departamento de Engenharia Química \\ ${ }^{2}$ WEG TINTAS, Guaramirim, SC \\ ${ }^{3}$ Universidade Federal de Santa Catarina, Departamento de Engenharia Química e Engenharia de \\ Alimentos \\ E-mail para contato: lucianoandre@yahoo.com
}

\begin{abstract}
RESUMO - As tintas em pó representam hoje uma moderna opção para acabamentos superficiais, devido à eliminação do uso de solvente em sua formulação e processo e também ao seu alto rendimento, podendo substituir tintas líquidas nas aplicações em metal, vidro e madeira. $\mathrm{O}$ presente trabalho teve por objetivo estudar a influência do reticulante nas propriedades das tintas em pó do tipo poliéster. Para o estudo do reticulante, foram elaboradas amostras com reticulantes triglicidil isocianurato (TGIC) e tereftalato de diglicidila (TD), com e sem antioxidantes, de forma a entender suas influências por meio dos testes de resistência ao impacto, brilho, gel time, cor e intemperismo acelerado. Os resultados revelaram que o sistema Poliéster/TGIC apresentou resultados de resistência mecânica de $160 \mathrm{~kg} . \mathrm{cm}$, medição de brilho de 94,5 UB, e reatividade(gel time) de $103 \mathrm{~s}$. Estes valores indicam resultados pouco superiores aos obtidos ao reticulante TD.
\end{abstract}

\section{INTRODUÇÃO}

A tinta em pó pode ser compreendida como um produto composto de componentes $100 \%$ sólidos. Uma mistura composta de polímeros (resinas), pigmentos, aditivos e cargas minerais que, após bem processados, se apresentam sob a forma de um composto único sob a forma de pó fino. Este pó, ao ser aplicado sobre superfícies metálicas tratadas exercerá sua função de acabamento e proteção através de sua polimerização e reatividade por aquecimento (Fazenda, 2005).

Uma das maiores fontes de poluição ambiental atualmente são as tecnologias e processos convencionais de acabamentos superficiais (Costa, 2002). No setor de linha branca, pintura de metais, vidros e até mesmo madeira, a situação não é diferente. Muito mais do que o uso do produto, da sua distribuição física, manutenção, materiais empregados, do seu processo de descarte ou resíduos gerados no fim de vida, os seus processos de fabricação, especialmente de acabamento de superfícies, como pintura e fosfatização, são os grandes responsáveis pelo impacto ambiental gerado por este setor industrial (Silva, 2009). 
Os pigmentos anticorrosivos, apesar de o seu objetivo principal ser a proteção anticorrosiva, ajudam na promoção da adesão. Esses produtos são sílicas amorfas (silicatos de cálcio) que baseiam seus mecanismos de proteção em intercâmbio iônico. Quando o agente corrosivo permeia na tinta, o silicato de cálcio captura íons $\mathrm{H}^{+}$e libera o cátion $\llbracket \mathrm{Ca} \rrbracket^{2+}$ que se precipita sobre a interface metal/tinta, impermeabilizando o substrato e promovendo a adesão (ABNT/NBR 11003, 2009).

Atualmente, o reticulante mais utilizado para a cura da tinta poliéster é o Triglicidil Isocianurato (conhecido como TGIC). Porém, novas propostas de reticulantes estão surgindo e devem ser cuidadosamente estudadas de forma a avaliar sua implementação. O reticulante Tereftalato de Diglicidila (tratado nesse trabalho como TD) tem sido amplamente utilizado por conferir uma melhor resistência ao amarelamento. Portanto, o trabalho avaliará novas propostas de reticulantes e qual o benefício das mesmas quando se trata em resistência ao intemperismo (ABNT/NBR 8094, 1983).

\section{MATERIAIS E MÉTODOS}

\subsection{Materiais}

A primeira etapa do presente trabalho visa à formulação e ao desenvolvimento das tintas com o propósito de analisar e comparar os sistemas de reticulação poliéster/TGIC em relação ao poliéster/TD. Na segunda etapa, o estudo será direcionado à busca por soluções para aderência das tintas em chapas de aço galvanizado, alumínio zincado e vidro, um problema recorrente para as empresas fabricantes de tintas em pó.

A fabricação das amostras de tinta em pó ocorreu em regime semi-contínuo, consistindo em pesagens precisas das matérias primas, seguidas do processo de pré mistura, extrusão, resfriamento, quebra, micronização e aplicação. As matérias primas foram separadas e pesadas conforme estabelecido na formulação do produto.

A homogeneização das matérias primas pesadas foi realizada por meio de agitação mecânica. A mistura foi extrusada a uma temperatura entre 75 e $110{ }^{\circ} \mathrm{C}$, que é a faixa de temperatura de fusão das resinas usadas, e evitando a separação devido à diferença de densidade e tamanhos de partícula dos materiais.

Após a etapa de extrusão, o material foi resfriado para evitar início de cura. O material passou por uma calandra resfriada com água localizada na saída da extrusora, que confere à tinta a forma de lâmina no estado sólido.

Após a extrusão, as lâminas foram recolhidas, colocadas em um novo recipiente plástico e trituradas com o auxílio de um martelo, a tinta foi então peneirada, para todos os casos em telas de 200mesh, permitindo um pó mais fino. 


\subsection{Preparação das amostras}

A limpeza mecânica foi realizada em uma cabine especial onde partículas abrasivas foram impulsionadas através de ar comprimido sobre a superfície do metal. Assim, o jateamento abrasivo remove a camada de óxidos de ferro (carepa) e outras substâncias depositadas sobre a superfície do metal. A limpeza química utilizada foi feita por imersão da peça em banho quente (entre 40 e $60{ }^{\circ} \mathrm{C}$ ) de produtos alcalinos, como hidróxido de sódio. Após o banho, foi realizada uma lavagem com esponja e detergente seguido de enxágue com água limpa. O pó moído e peneirado foi transportado por uma corrente de ar através da pistola eletrostático, que tiveram os seus eletrodos conectados a um gerador de alta voltagem (30 a $100 \mathrm{KV}$ ). O pó adquiriu assim carga eletrostática de polaridade negativa.

O objeto a ser pintado apresentou polaridade positiva e potencial zero. As partículas carregadas eletricamente submetidas à influência do campo elétrico criado pelos eletrodos da pistola foram atraídas para a superfície do objeto a ser pintado, como mostra a Figura 1, formando uma camada que pode recobrir inclusive a superfície oposta ao sentido da aplicação. a cura foi feita a $200{ }^{\circ} \mathrm{C}$ por 10 minutos, considerando temperatura da peça e independente da massa e do volume.

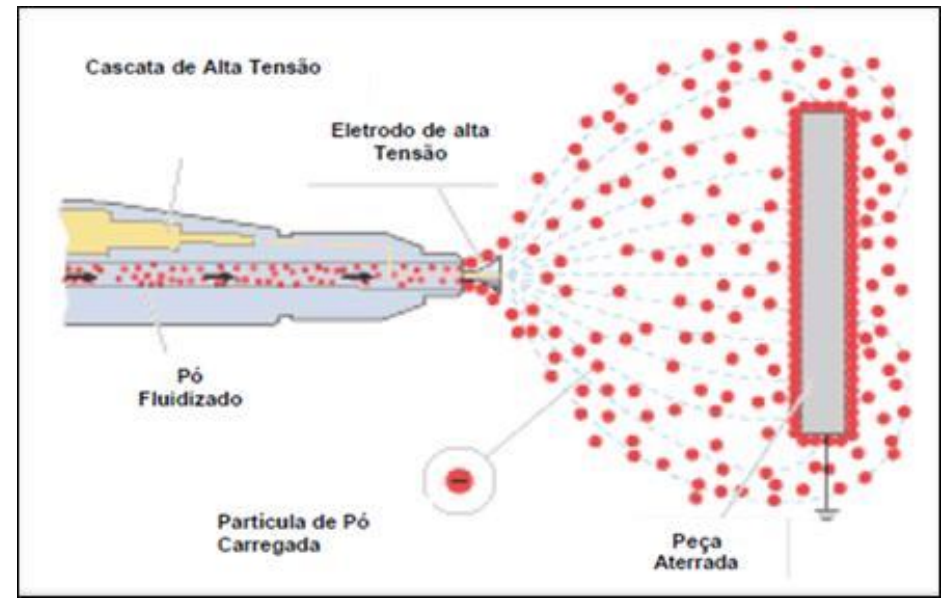

Figura 1 - Mecanismo de carga elétrica das partículas durante a aplicação (Silva, 2009).

\subsection{Estudo da reticulação}

Para estudar a influência da reticulação da tinta e seu grau de interferência, foram elaboradas tintas de coloração branca por ser a mais susceptível ao amarelamento e às interferências do meio externo. Foram utilizados os seguintes componentes na formulação de cada amostra: resina, reticulante, dióxido de titânio (pigmento branco), benzoína (aditivo desgaseificante), antioxidante (aditivo), sulfato de bário (carga) e sílica (aditivo - auxilia na moagem e peneiramento).

Para avaliar os novos reticulantes à base de tereftalato de diglicidila (TD) com resinas poliéster, foram elaboradas as amostras de 1 a 3 . As resinas poliéster do tipo A foram 
desenvolvidas para reagir com o reticulante triglicidil isociunarato (TGIC), portanto, para confrontar a influência das resinas, a amostra 4 foi elaborada com uma resina poliéster própria para reticulantes TD, a resina do tipo B. A amostra 5 foi elaborada para contrastar os sistemas Poliéster/TGIC e Poliéster/TD. As amostras de 6 a 11 foram elaboradas a fim de comparar a resistência ao impacto e amarelamento utilizando antioxidantes. A Tabela 1 apresenta as formulações propostas no presente trabalho.

Tabela 1 - Formulações propostas para avaliação das propriedades das tintas em pó.

\begin{tabular}{|c|c|}
\hline Amostra & Formulação proposta \\
\hline 1 & Resina Poliéster A e Reticulante TD 1 (Padrão) \\
\hline 2 & Resina Poliéster A e Reticulante TD 2 (Novo) \\
\hline 3 & Resina Poliéster A e Reticulante TD 3 (Novo) \\
\hline 4 & Resina Poliéster B e Reticulante TD 2 (Novo); \\
\hline 5 & Resina Poliéster/TGIC e Resina Poliéster/TD \\
\hline 6 & Resina A e Reticulante TD 1 sem antioxidante \\
\hline 7 & Resina A e Reticulante TD 2 sem antioxidante \\
\hline 8 & Resina A e Reticulante TD 1 com antioxidante X (Padrão) \\
\hline 9 & Resina A e Reticulante TD 2 com antioxidante X (Padrão) \\
\hline 10 & Resina A e Reticulante TD 2 com antioxidante Y (Novo) \\
\hline 11 & Resina A e Reticulante TD 2 com antioxidante Z \\
\hline
\end{tabular}

Todas as amostras sofreram extrusão e reextrusão de $1 \mathrm{~kg}$ de cada amostra, os testes foram moídos e peneirados em tela \#200 (mesh). Em uma primeira bateria de testes, as amostras foram curadas em estufa a $200{ }^{\circ} \mathrm{C}$ por 10 minutos, com camada de $60-80 \mu \mathrm{m}$, em chapa de aço de 7 x $20 \mathrm{~cm}$ para avaliação da resistência ao impacto (ASTM D 2794-93, 1999). Para avaliar a alteração de cor, um segundo conjunto de amostras foi curado em estufa a $200^{\circ} \mathrm{C}$ por $20 \mathrm{~min}$, teste chamado de sobrecura (ASTM D 1535, 1969). Um terceiro conjunto de amostras foi pintado em placas de alumínio 7 x $15 \mathrm{~cm}$, camada de $60-80 \mu \mathrm{m}$ e curados por 10 minutos a $200^{\circ} \mathrm{C}$ para a realização dos testes de Intemperismo acelerado (ASTM B 117-07, 2007).

\section{RESULTADOS E DISCUSSÃO}

O grau de reticulação da tinta está fortemente ligada à resistência ao impacto que esta oferece. Quanto maior for o grau de reticulação da mesma, quanto melhor for a reação entre resina e reticulante, maior será a resistência que a tinta tem à impactos. A Tabela 1 mostra o resultado dos testes de impacto. Para uma tinta ser aprovada por resistência ao impacto deve apresentar resultados superiores a $50 \mathrm{~kg} . \mathrm{cm}$ (ASTM D 2794-93, 1999). 
Tabela 2 - Avaliação da Resistência ao Impacto

\begin{tabular}{|c|c|c|}
\hline \multicolumn{3}{|c|}{ Resistência ao Impacto } \\
\hline Amostra & Formulação & Resultado (kg.cm) \\
\hline 1 & Resina A/TD1 & 160,0 \\
\hline 2 & Resina A/TD2 & 160,0 \\
\hline 3 & Resina A/TD3 & 60,0 \\
\hline 4 & Resina B/TD1 & 60,0 \\
\hline 5 & Resina A/TGIC & 160,0 \\
\hline 6 & TD 1/Sem Antioxidante & 80,0 \\
\hline 7 & TD 2/Sem Antioxidante & 40,0 \\
\hline 8 & TD 1/Antioxidante X & 140,0 \\
\hline 9 & TD 2/Antioxidante X & 160,0 \\
\hline 10 & TD 2/Antioxidante Y & 160,0 \\
\hline 11 & TD 2/Antioxidante Z & 40,0 \\
\hline
\end{tabular}

A Tabela 2 mostra a forte influência que os antioxidantes oferecem à resistência ao impacto. A radiação existente na própria estufa interage com as ligações covalentes ao longo do polímero e causa o rompimento das cadeias, o que facilita a deterioração das mesmas pela ação do oxigênio. $\mathrm{O}$ antioxidante ao atuar contra esse processo de oxidação, evita que essas cadeias sejam quebradas e faz com que a rede polimérica formada pela reação entre resina e reticulante seja mais robusta tornando a tinta mais resistente ao impacto. A ausência desse aditivo acarreta em cadeias mais frágeis, como se observa pelo resultado da Amostra 7 (sem antioxidante) que apresentou resultado inferior ao especificado. O Antioxidante $\mathrm{Z}$ (presente na formulação 11) também apresentou resistência abaixo do especificado, sendo reprovado.

O sistema resina/reticulante também influencia consideravelmente. A resina A apresentou excelentes resultados quando reticuladas pelos compostos TD 1, TD 2 e TGIC. Isso se deve à maior ou menor afinidade existente entre as moléculas dos reticulantes e das moléculas do polímero em questão. Já o reticulante TD 3 (Amostra 3) e a resina B (Amostra 4), apesar de apresentarem resultados superiores ao especificado, ficaram abaixo das outras amostras nas mesmas condições. Este teste demostra a importância da realização de testes entre diferentes resinas/reticulantes/antioxidantes a fim de selecionar quais matérias-primas devem reagir entre si para gerarem tintas em pó mais resistentes possíveis. Portanto, para este caso, as amostras que contêm resina A associada a qualquer dos reticulantes TD 1, TD 2 ou TGIC acompanhadas dos antioxidantes X e Y, podem ser consideradas como excelentes tintas resistentes ao impacto. 
Para medição de brilho, várias medidas foram realizadas em uma mesma chapa e os valores médios para cada amostra. A reatividade das tintas foi realizada em triplicata, para minimizar possíveis erros do ensaio. Os resultados da medição de brilho e ensaio de reatividade estão apresentados na Tabela 3.

Tabela 3 - Medição de brilho - cura a $200^{\circ} \mathrm{C}$ por $10 \mathrm{~s}$. Ensaio de reatividade.

\begin{tabular}{|c|c|c|c|c|c|}
\hline \multicolumn{3}{|c|}{ Brilho $60^{\circ}$} & \multicolumn{3}{|c|}{ Gel Time } \\
\hline Amostra & Formulação & $\begin{array}{l}\text { Resultado } \\
\text { (UB) }\end{array}$ & Amostra & Formulação & Tempo (s) \\
\hline 1 & $\begin{array}{l}\text { Resina } \\
\text { A/TD1 }\end{array}$ & 89,08 & 1 & $\begin{array}{l}\text { Resina } \\
\text { A/TD1 }\end{array}$ & 55,0 \\
\hline 2 & $\begin{array}{l}\text { Resina } \\
\text { A/TD2 }\end{array}$ & 89,76 & 2 & $\begin{array}{l}\text { Resina } \\
\text { A/TD2 }\end{array}$ & 44,0 \\
\hline 3 & $\begin{array}{l}\text { Resina } \\
\text { A/TD3 }\end{array}$ & 92,18 & 3 & $\begin{array}{l}\text { Resina } \\
\text { A/TD3 }\end{array}$ & 53,0 \\
\hline 4 & Resina B/TD1 & 95,20 & 4 & Resina B/TD1 & 124,0 \\
\hline 5 & $\begin{array}{l}\text { Resina } \\
\text { A/TGIC }\end{array}$ & 94,50 & 5 & $\begin{array}{l}\text { Resina } \\
\text { A/TGIC }\end{array}$ & 103,0 \\
\hline 6 & $\begin{array}{c}\text { TD 1/Sem } \\
\text { Antioxidante }\end{array}$ & 92,00 & 6 & $\begin{array}{c}\text { TD 1/Sem } \\
\text { Antioxidante }\end{array}$ & 61,0 \\
\hline 7 & $\begin{array}{c}\text { TD 2/Sem } \\
\text { Antioxidante }\end{array}$ & 94,20 & 7 & $\begin{array}{c}\text { TD 2/Sem } \\
\text { Antioxidante }\end{array}$ & 62,0 \\
\hline 8 & $\begin{array}{c}\text { TD } 1 \\
\text { /Antioxidante } \\
\text { X }\end{array}$ & 94,80 & 8 & $\begin{array}{c}\text { TD } 1 \\
\text { /Antioxidante } \\
\text { X }\end{array}$ & 64,0 \\
\hline 9 & $\begin{array}{c}\mathrm{TD} 2 \\
\text { /Antioxidante } \\
\mathrm{X}\end{array}$ & 94,50 & 9 & $\begin{array}{c}\text { TD2 } \\
\text { /Antioxidante } \\
\text { X }\end{array}$ & 59,0 \\
\hline 10 & $\begin{array}{c}\text { TD } 2 \\
\text { /Antioxidante } \\
\text { Y }\end{array}$ & 95,30 & 10 & $\begin{array}{c}\text { TD } 2 \\
\text { /Antioxidante } \\
\text { Y }\end{array}$ & 62,0 \\
\hline 11 & $\begin{array}{c}\text { TD } 2 \\
\text { /Antioxidante } \\
\text { Z }\end{array}$ & 94,80 & 11 & $\begin{array}{c}\text { TD } 2 \\
\text { /Antioxidante } \\
\text { Z }\end{array}$ & 62,0 \\
\hline
\end{tabular}


Os resultados para todas as amostras, tanto para sistema TGIC quando para sistema TD e independente do antioxidante utilizado se mostraram muito semelhantes no quesito brilho.

O valor médio da reatividade de cada amostra está inserido na Tabela 3. A amostra que apresentou menor tempo de cura foi a Amostra 2 (Resina A e TD 2) e a tinta com maior tempo de reação foi a Amostra 4 (Resina B e TD 2). Essa informação é importante para avaliar se as condições da estufa ofereceram o meio adequado para a cura de cada tinta. Essa avaliação também é importante para certificar de que o reticulante foi adicionado na formulação. Para todas as amostras, o tempo e temperatura de cura foram adequados.

A fim de simular a ação do meio ambiente sobre as tintas, faz-se necessária a aplicação do ensaio de 500h de Intemperismo Acelerado QUV-B. A Tabela 4 apresenta um comparativo da medição de brilho entre as chapas submetidas ao teste QUV-B e as que não passaram.

Tabela 4 - Medição de Brilho $60^{\circ}$ após 500h de Intemperismo Acelerado - QUV-B.

\begin{tabular}{|c|c|c|c|c|c|}
\hline \multicolumn{3}{|c|}{ Brilho 60 ${ }^{\circ}$ após aplicação } & \multicolumn{2}{c|}{$\begin{array}{c}\text { Brilho 60 }{ }^{\circ} \text { após 500h } \\
\text { QUV-B }\end{array}$} & $\begin{array}{c}\text { Redução do } \\
\text { Brilho }\end{array}$ \\
\hline Amostra & $\begin{array}{c}\text { Breve } \\
\text { Descrição }\end{array}$ & $\begin{array}{c}\text { Resultado } \\
\text { (UB) }\end{array}$ & Amostra & Resultado (UB) & $(\%)$ \\
\hline 1 & Resina A/TD1 & 95,84 & 1 & 41,00 & 57,22 \\
\hline 2 & Resina A/TD2 & 94,94 & 2 & 47,68 & 49,78 \\
\hline 3 & Resina A/TD3 & 96,20 & 3 & 43,50 & 54,78 \\
\hline 4 & Resina B/TD1 & 91,10 & 4 & 44,30 & 51,37 \\
\hline 5 & Resina A/TGIC & 95,70 & 5 & 36,90 & 60,62 \\
\hline
\end{tabular}

Após as $500 \mathrm{~h}$ de intemperismo acelerado, todas as amostras apresentaram uma queda significativa de brilho. Na leitura de cor, a Amostra 2 (Resina A/TD 2), Amostra 4 (Resina B/TD2) e 5 (Resina A/TGIC) apresentaram a menor variação, o que não ocorreu com as Amostras 1 (Resina A/TD1) e 3 (Resina A/TD3), já que apresentaram uma variação maior quando comparadas à variação da sobrecura. Sendo assim, as matérias-primas TGIC e TD2 mais uma vez se apresentaram superiores na manutenção da coloração e brilho para tintas que serão expostas à ação do meio ambiente. Este fato pode ser explicado pela excelente afinidade que a resina A teve tanto com TD 2 quanto com o TGIC e a resina B com TD2. Esta afinidade provocou durante a cura uma complexidade maior das reticulações da tinta que dificulta o processo de oxidação. 


\section{CONCLUSÃO}

De acordo com os resultados obtidos no estudo da reticulação, pode-se concluir que os reticulantes mais adequados para reagir com poliéster foram o TGIC e o TD2. O reticulante TD 2, além de permitir uma melhor cobertura da cor branca na superfície das chapas, melhorou o impacto quando comparado ao TD 1 na presença do antioxidante X. Já o Reticulante TD 3 não apresentou resultados satisfatórios, visto que não se destacou em nenhum teste quando comparado às outras amostras e conferiu à tinta uma resistência ao impacto pouco significativa. Porém, ainda assim o reticulante TD 2 apresentou qualidade superior tanto na manutenção do padrão de cor e brilho nas tintas em aplicações diversas.

\section{REFERÊNCIAS}

ABITIM; ABRAFATI; Guia Técnico Ambiental Tintas e Vernizes -São Paulo, 2006.

ASTM - AMERICAN SOCIETY FOR TESTING AND MATERIALS. ASTM B 117-07: Standard Practice for Operating Salt Spray (Fog) Apparatus, Washington, D.C 2007.

ASTM - AMERICAN SOCIETY FOR TESTING AND MATERIALS. ASTM D 1535: Standard Method of Specifying Color by the Munsell System. Washington, D.C., 1969.

ASTM - AMERICAN SOCIETY FOR TESTING AND MATERIALS. ASTM D 2794-93: Standart Test Method for Resistance of Organic Coatings to the Effects of Rapid Deformation (Impact). Washington, D.C., 1999.

ASTM - AMERICAN SOCIETY FOR TESTING AND MATERIALS. ASTM D 4541: PullOff Strength of Coatings Using Portable Adhesion Testers. Philadelphia, USA, 2005.

ABNT - ASSOCIAÇÃO BRASILEIRA DE NORMAS TÉCNICAS. NBR 8094: Ensaio de Corrosão por Exposição à Névoa Salina. Rio de Janeiro, 1983.

ABNT - ASSOCIAÇÃO BRASILEIRA DE NORMAS TÉCNICAS. NBR 11003: Tintas determinação da aderência. Rio de Janeiro, 2009.

COSTA M. F. B., COSTA M. A. F. Exposição Ocupacional a Compostos Orgânicos Voláteis na Indústria Naval. Química Nova, Vol. 25, n³, 384-386, 2002.

FAZENDA, Jorge M. R. Tintas e Vernizes Ciência e Tecnologia. $3^{\mathrm{a}}$ ed. São Paulo: ABRAFATI, 2005.

SILVA, S. D. Pintura Industrial em Pó. $3^{\text {a }}$ ed. Guaramirim: WEG Tintas, 2009. 